\title{
REDESCRIPTION AND SYSTEMATIC STUDIES ON PROCAMALLANUS (PROCAMALLANUS) ELATENSIS FUSCO \& OVERSTREET, 1979 FROM THREE RED SEA SIGANUS SP. FISHES By
}

REFAAT M.A. KHALIFA ${ }^{1^{*}}$, HODA S. MOHAMADAIN ${ }^{2^{* *}}$ and YASSER F.M. KARAR ${ }^{2}$ Department of Medical Parasitology, Faculty of Medicine, Assiut University ${ }^{1}$, and Department of Zoology, Faculty of Science, Qena, South Valley University, Egypt

( ${ }^{\star}$ Correspondence: rkhalifa_eg@yahoo, **hoda.abdelgalil@sci.svu.edu.eg)

\begin{abstract}
As part of an on-going study of the helminthes parasitizing fish from the Red Sea; Hurghada, Egypt, Procamallanus (Procamallanus) elatensis Fusco \& Overstreet, 1979 was collected from three different Siganus fish species (S. rivulatus, S. luridus \& S. sutor). It was morphologically elucidated and examined by light and scanning electron microscopy which indicated evident previous erroneous descriptions of both the anterior position of the excretory pore at nerve ring level and absence of deirids, to be excretory pore somewhat posterior to junction of the oesophageal parts and presence of a posterior pair of deirids, located posterior to mid-body level by small distance.Furthermore, the present detailed comparisons against the most similar Procamallanus species, casted doubt about the validity of P. sigani Yamaguti, 1935 and $P$. lonis Yamaguti, 1941 which could be considered as two different biological variations of Procamallanus (P.) elatensis.
\end{abstract}

Keywords: Egypt, Red Sea fishes, Procamallanus (Procamallanus) elatensis, Siganus species, SEM

\section{Introduction}

The genus Procamallanus was created by Baylis, 1923 with P. laeviconchus (Wedl, 1862 ) as its type species. While creating this genus he also described Procamallanus spiralis from a single male specimen from a siluroid fish Hetrobranchus anguillaris from the Nile River at Cairo. Annereaux (1946) developed a key for 22 existing species of the genus Procamallanus at that time. In 1952, Olsen divided the genus into two subgenera Procamallanus and Spirocamallanus where the genus Procamallanus was restricted to those species having a smooth buccal capsule lining whilst Spirocamallanus was characterized by spiral thickening on the inner wall of the buccal capsule. Khera (1955) and Ali (1956, 1960) modified the key developed by Annereaux (1946) for the identification of the species of the original genus Procamallanus without consideration to Olsen (1952) division. Shing (1960) indicated the validity of both genera Procamallanus and Spirocamallanus. They also commented on Ali $(1956,1960)$ keys particularly about including $P$. gubernaculus in Procamallanus subgenera and not in Spirocamallanus in spite of having only one spic- ule. Sahay (1966) presented a key representing a modification of Annereaux's, Khera's and Ali's keys to genus Procamallanus. In this key, the taxonomical structure of the genus Procamallanus was reassigned to include five subgenera; Aspiculus (Ali, 1960), Monospiculus (Ali, 1956) Isospiculus (Ali, 1956), Procamallanus Baylis, 1923 \& )Ali, 1956) and Spirocamallanus Olsen, 1952.

Several attempts were made to construct a key to the subgernera of this genus. Moravec $\&$ Thatcher (1997) presented five subgenera: Procamallanus Baylis, 1923; Spirocamallanus Olsen, 1952; Spirocamallanoides (Mor avec and Sey, 1988); Punctocamallanus (Moravec and Scholz, 1991) and Denticamallanus (Moravec and Thatcher, 1997). This math was exactly the most recent taxonomic structuring adapted by Gibson (2017).

The most known species of Procamallanus reported from the Red Sea region was Procamallanus (Procamallanus) elatensis (Fusco and Overstreet, 1979; Abdou et al, 1995; Abdou et al, 2001; Al-Jahdali, 2012).

\section{Materials and Methods}

Fish specimens were collected from Northern Red Sea, Off Sharm El-Naga, Makadi 
Bay, Southern Hurghada, Egypt (Depth = $0.5-2.5 \mathrm{~cm}$ ) and were transported as alive as possible with good aeration and cooling immediately to the laboratory of Parasitology, Zoology Department, Faculty of Science, South Valley University at Qena Governorate, Egypt. Fishes were identified according to criteria established by Randall (1982), Lieske and Myers (1994, 1996) and Lieske et al. (2004) and more confirmed through the fish base website (http://www. fishbase.org). The gastrointestinal tract was untangled with fingers (Justine et al, 2012). The whole digestive system and the remaining other viscera were opened longitudinally. Macroscopic and microscopic examination of different organs was carried out for detection of any visible nematod parasites. The collected parasites were cleaned by washing several times with isotonic saline solution. The relaxed nematodes were preserved in bottles containing mixture of $70 \%$ alcohol and 5\% glycerin. Coiled nematodes were transferred into warm $70 \%$ alcohol heated to $60^{\circ} \mathrm{C}$. The nematodes were mounted on slides with few drops of lactophenol and the parasite was covered by a cover slip. Identification of the encountered worms was done according to the keys of the nematode parasites of vertebrates (Yorke et al., 1926; Anderson, 2000; Anderson et al., (2009). For SEM studies specimens were fixed for 6 hours at $4^{\circ} \mathrm{C}$ in $2.5 \%$ glutaraldehyde in 0.1 $\mathrm{M}$ sodium cacodylate buffer, washed several times in the same buffer at $4{ }^{\circ} \mathrm{C}$. post fixed in $1 \%$ osmium tctroxide (OSO4) for 2 hours at 4 "C, washed two times in cacodylate buffer, dehydrated in ascending grades of ethanol series and transferred into pure acetone. Samples were then processed in a critical point drier "Bomer - 900" with Freon 13. Samples were sputter coated with gold in a Technics Hummer V (Lee, 1993) and viewed with a JEOL JSM-5400LV SEM operated at $15 \mathrm{kV}$ in electron microscopy unit, Assiut University

\section{Results}

Incidence: Out of 94 collected; three dif- ferent Siganus fish species [(70) S. rivulatus, (8) S. luridus \&(16) S. sutor]; 58, $6 \& 12$ fishes respectively were found infected with Procamallanus (Procamallanus) elatensis (Fusco and Overstreet, 1979) in their small intestine; worm burden was 1-35, 1-4, 8-18 /fish host respectively..

Morphological re-description: Based on 14 mature specimens; 5 males \& 9 females (Pls $1,2 \& 3)$, measurements, morphometric percentages and morphometric ratios (Tab. 1).

Alive specimens were reddish fixed specimens light yellowish brown to somewhat deep brown. Medium-sized nematodes with finely transversely striated cuticle extending from posterior region of buccal capsule to posterior extremity of body, Maximum width at mid-body level or slightly anterior, Mouth aperture circular, dorso-ventrally elongate, surrounded by thin translucent membrane with six flat, crescent-shaped elevations and four submedian cephalic papillae (Pl. 1B\&C; Pl.2A-C; Pl.3A\&B). Small lateral amphids present with origins external to those of papillae. Buccal capsule sclerotized, greenish light yellow-brown, thickwalled, barrel shaped, with well-developed basal ring; basal, narrowed part of buccal capsule proper anterior to basal ring somewhat thickened, forming apparent circular ledge (Pl. 1A-C; Pl.2A-C; Pl. 3A). The buccal capsule borders well-differentiated from inside part by its dark color whereas, the inner surface of capsule has more light color, Also, inner surface of capsule smooth, without any spiral ridges (Pl.1A-C; Pl. 2A$\mathrm{C}$; Pl. 3A\&B). Oesophagus divided into two parts; anterior muscular portion moderately club-shaped and posterior glandular portion elongate, ending with paired bilobed valves. Both oesophageal parts slightly swelled near their posterior ends, Intestine brown, narrow [Pl. 1A; Pl, 2A). Anterior deirids small, simple, situated some distance anterior to nerve ring level ( $\mathrm{Pl} .3 \mathrm{~A})$, Nerve ring situated at the end first third level of muscular oesophagus or at the beginning of its second half (Pl. 1C; Pl. 2 B\&C), Excretory pore 
somewhat posterior to junction of both oesophageal parts (Pl. 3C\&D), Tail of both sexes conical.

Male: Testis straight, with anterior tip blunt end near region of upper intestine, Posterior end of body ventrally arcuate, provided with wide, vesiculated caudal alae of striated margins and supported by papillae; the anterior portion of alae interconnected by mound, forming thus a kind of pseudo sucker, and posteriorly reaching to tail, $\mathrm{Pa}$ pillae eight pairs in number, pedunculate, elongate, symmetrical and differentiated into two groups; a) pre-cloacal group represented by 3 equally spaced subventral pairs and decreasing in size posteriorly. b) Post-cloacal group of 5 anterior sub-ventral (Pl. 1D\&E \& $\mathrm{Pl}, 3 \mathrm{E} \& \mathrm{~F})$, A pair of lateral phasmids of slightly smaller and immediately posterior to last pair of post-cloacal papillae (Pl. 1D\&E). Spicules similar in shape, unequal, tapering posteriorly, with smooth surface, each with conspicuous posterior curvature with blunt alated distal tip [Plate $3 \mathrm{E} \& \mathrm{G}$ ]; small spicule somewhat less sclerotized. Gubernaculum $\mathrm{V}$-shaped with well sclerotized plate joining right side with shorter left side (Pl. 1D). Tail conical, with rounded tip.

Female: Vulva pre-equatorial. Anterior vulva lip somewhat elevated, Vagina muscular, straight, extending posteriorly from vulva, Uterus J-shaped, and saccular, Oviducts usually straight, directed posteriorly. Ovaries straight, directed posteriorly. Rectum is moderately short, and surrounded by four rectal glands arranged into two columns of two along length of rectum. Tail is conical, with blunt tip and two slightly outlined protuberances (Pl. 2D-G; Pl.3H).

Ultra-structure: Using SEM revealed in both genders that; the cephalic head (anterior extremity) is bulb-like. Mouth aperture rounded surrounded by small thin peribuccal collar with a hexagonal peripheral margin and supported with six flat, crescent-shaped cephalic plates. Two groups of cephalic papillae; the inner group consisted of six small spherical papillae, each one situated over the anterior extremity of each the cephalic plate whereas, the outer group consisted of four spherical large papillae which distributed among the bases of the cephalic plates. Two small amphids were observed adjacent to and on opposite sides of the peribuccal collar (Pl. 3A\&B).

The cuticle is provided with transverse striations extending from posterior region of the cephalic head to posterior extremity of body. Several longitudinal wavy thickenings from the cuticle extend from the beginning of transverse striations level anteriorly and ramify to several smaller branched near the base of the cephalic plates (Pl. 3C\&D). Deirids divided into two pairs; anterior deirids represented by a pair of small, dorsoventrally flattened structures at about the end of the first tenth of body length (Pl. 3A). The other posterior pair of deirids is slightly smaller, dorso-ventrally flattened and situated posterior to mid-body level by small distance (Pl. 3B).

The male posterior end is ventrally arcuate, forming 1-2 coils, provided with two asymmetrical lateral alae extended on both sides of posterior end. Caudal papillae are eight pairs, with symmetrical spherical end differentiated into two groups; a) pre-cloacal group represented by 3 equally spaced subventral pairs and decreasing in size posteriorly. b) Post-cloacal group of 5 anterior subventral pairs; $2^{\text {nd }} \& 5^{\text {th }}$ pair are the smallest (Pl. 3 F). A pair of lateral phasmids of was slightly smaller than and immediately posterior to last pair of post-cloacal papillae (Pl. $3 \mathrm{E})$. The large spicule erected well from the cloaca, tapering posteriorly, with conspicuous posterior curvature and smooth surface; small spicule retracted inside cloaca (Pl. 3 $\mathrm{E} \& \mathrm{G})$. Tail conical, with rounded tip (Pl. $3 \mathrm{E})$.

The posterior end of the female straight with conical tail ended with blunt tip and two slightly outlined protuberances. The anus opening represented by a narrow transvers slit-like opening $(\mathrm{Pl} .3 \mathrm{H})$. 


\section{Discussion}

The incidence of infection in siganid fishes in the present study indicates that the present parasite is a very common inhabitant of the siganid fishes in Red Sea at Hurghada. With the following characteristics: not heterogenetic, parasitic forms sexually differentiated, esophagus not consisting of a narrow tube running through the center of single cells and not dilated posteriorly into a bulb, male posterior end without copulatory bursa, head without any lobes, presence of chitinous buccal cavity, vulva posterior mid-level of body by a small distance and parasitic in alimentary canal give evidence that collected specimens belong to the Superfamily Camallanoidea Travassos, 1920. Furthermore, the combined features; sexual dimorphism not marked, cephalic head without any appendages and presence of large chitinous buccal cavity place newly collected specimens inside the family Camallanidae Railliet \& Henry, 1915 (Yorke et al, 1926) The smooth and continuous buccal capsule without differentiation into paired lateral valves indicated that the present specimens belong to the genus Procamallanus Baylis, 1923 (Sahay and Narayan, 1967) and absence of the internal spiral thickenings from the buccal capsule places the present specimens inside the subgenus Procamallanus Baylis, 1923 (Sahay, 1966; Moravec and Thatcher, 1997).

Concerning the comparison among newly collected specimens with the previously described forms of the subgenus Procamallanus, great similarity and a high converge with Procamallanus (Procamallanus) elatensis (Fusco and Overstreet, 1979) in overall appearance and almost body parts dimensions in both genders was found. However, large number of allometric measurements were almost similar including; maximum body width, buccal capsule length, both muscular and glandular oesophagus length, pre-nerve ring distance, tail length, caudal alae length and rectum length as a percentage of body length. Moreover, great simi- larities in ratios of buccal capsule width/ length, glandular oesophagus/muscular oesophagus length and spicules length.

On the other hand, the present specimens exhibit some difference against the previously described $P$. elatensis by Fusco and Overstreet (1979); excretory pore somewhat posterior to junction of both oesophageal parts not anterior to nerve ring and present specimens have a pair of posterior deirids located posterior to mid-body level by small distance. The present SEM showed some difference from that of Abdou et al. (2001) including: i) the top of the mouth is characterized by a scleretized plate but not attached by three arms to the inner edge of the collar; ii) the excretory pore located posterior to junction of both oesophageal parts not opening in the first third of the body; iii) no lateral papillae on the lateral side of the worm body observed and iv) the total number of papillae on male posterior end in the present study was 8 pairs (3 pre-cloacal pairs \& 5 post-cloacal pairs) not 12 pair (4 pre-cloacal pairs, 4 lateral papillae pairs \& 4 post-cloacal pairs).

In the present study, the specimens are very similar to $P$. elatensis and with detailed morphometric features consistent with Moravec and Justine (2011) data and confirmed that the position of the excretory pore anterior to the level of nerve ring (Fusco and Overstreet, 1979) or it opens in the first third of the body (Abdou et al, 2001) and the absence of deirids (Fusco and Overstreet, 1979 ) in P. elatensis were evidently erroneous. According to the host-parasite data several species of subgenus Procamallanus were reported from several Siganus fish spp. off the Indo-Pacific region. Three of them were the most similar to present material $P$. elatensis: P. sigani Yamaguti, 1935 [from S. fus-cescens off Inland Sea of Japan and Pacific coast of Mie and Wakayama Prefectures (Yamaguti, 1935); from both S. guttatus and S. oramin off North Borneo, Malaysi a (Myer and Kuntz,1969), from S. sutor off the Kenyan coast (Martens and Moens, 
1995; Geets and Ollevier, 1996) and off Kilifi (Aloo et al., 2004); P. lonis (Yamaguti, 1941) from $S$. unimaculatus off Okinawa, Japan (Yamaguti,1941); from both S. lineatus and S. punctatus off the Great Barrier Reef, Australia (Lester \& Sewell, 1989)]; P. annulatus Yamaguti, 1955 [from Siganus sp. off Celebes, Indonesia (Yamaguti, 1955); from S. stellatus off Colombo Sri Lanka (Parukhin, 1971); from S. lineatus off New Caledonia (Moravec and Justine, 2011).

The incomplete original descriptions of both $P$. sigani and $P$. lonis, their overlapped measurements with $P$. elatensis specimens and absence of modified new descreptions of both two species with poor conditions of their type specimens preventing their reexamination (Moravec and Justine, 2011), casted doubt about the validity of both $P$. sigani and $P$. lonis and considering them as two different biological variations of $P$. elatensis.

Generally, $P$. elatensis is differentiated from the previously described and redescribed species by the largest value of length ratio of spicules (1:1.78-3.30), spicules with blunt tips, the gubernaculum V-shaped and weakly sclerotized and presence of posterior deirids; $P$. sigani can be differentiated by absence of a both gubernaculum and a distinct ledge adjacent to the buccal capsule's basal ring (Yamaguti, 1935); P. annulatus characterized by small spicules length ratio (1:1.1-1.5), gubernaculum non-bifurcated and strongly sclerotized (Yamaguti, 1955; Moravec and Justine, 2011); P. lonis is the most similar species to $P$. sigani but differs from it in having pointed spicules, caudal alae continuous anteriorly not separated and presence of a distinct ledge adjacent to the buccal capsule's basal ring (Yamaguti, 1941). The previously discussed morphological changes and differences in allometric measurements between Fusco and Overstreet (1979) measurements and present study may be attributed to; 1) the differences in overall size of the worms which could simply reflect differences in the age of the worms which affect several measurement. (2) All previously described and present specimens collected at different distant times, so the environmental conditions and changes should best be taken in consideration.

The host-parasite data indicated that $P$. sigani is the only known nematode parasite reported from Siganus sutor. Hence, Siganus sutor is herein reported as a new host record of Procamallanus (Procamallanus) elatensis (Fusco and Overstreet, 1979.

Conclusion: As part of an on-going study of the helminthes parasitizing fish from the Red Sea; Hurghada, Egypt, Procamallanus (Procamallanus) elatensis Fusco and Overstreet, was collected from three different Siganus fish species (S.rivulatus, S. luridus $\& S$. sutori). It was morphologically elucidated and examined by light and scanning electron microscopy which indicated evident previous erroneous descriptions of both the anterior position of the excretory pore at nerve ring level and absence of deirids to be excretory pore somewhat posterior to junction of both oesophageal parts and presence of a posterior pair of deirids, located posterior to mid-body level by small distance. Also, the present light and SEM studies added and corrected many morphometric and fine details of the parasite and casted doubt about validity of $P$. sigani Yamaguti, 1935 \& P. lonis Yamaguti, 1941 that could be considered as two different biological variations of Procamallanus $(P)$ elatensis.

\section{Conclusion}

The parasite was for the first time reported from Red Sea fishes at Hurghada with addition of many morphometric and ultra-structural details and Siganus sutor is reported as a new fish host record of Procamallanus (Rocamallunus) elatensis.

\section{References}

Abdou, NE, Ashour, AA, Heckmann, RA, Gardner, JS, 2001: Fine structure, range extension and re-description of Procamallanus elatensis, Fusco and Overstreet, 1979 (nematoda: camallanidae) from siganid fishes in the Red Sea, Egypt. J. Parasitol. 30:1-13. 
Abdou, NE, Heckmann, RA, Gardner, JS, Ashour, AA, 1995: Microscopic study of Procamallanus elatensis, a parasite in siganids, Red Sea Fish in Egypt. Proc. Microsco. Microanal. 79:1028-9.

Ali, S.M., (1956): Studies on the nematode parasites of fishes and birds found in Hyderabad State, Ind. J. Helminth., $8:$ 1-83.

Ali, S.M.(1960): On two new species of Procamallanus Baylis, 1923 from India, with a key to the species. J. Helminth., 32: 129-138.

Al-Jahdali, MO, 2012: Infrapopulations of Procamallanus elatensis Fusco \& Overstreet, 1979 (Nematoda: Camallanidae) in rabbitfish Siganus rivulatus (Teleostei, Siganidae) from the Saudi coast of the Red Sea. J. Helminthol. 86, 3:37885.

Aloo, PA, Mwangi, JN, Anam, RO, 2004: Metazoan parasites of some commercially important fish along the Kenyan coast. West. Indian Ocean J. Mar. Sci. 3, 1:71-8.

Anderson, RC, 2000: Nematode Parasites of Vertebrates: Their development and transmission. $2^{\text {nd }}$ edition. CABI, Wallingford, Oxon (UK).

Anderson, RC, Chabaud, AG, Willmott, S, 2009: Keys to the nematode parasites of vertebrates: archival volume CABI, Wallingford, Oxon (UK).

Annereaux, RF, 1946: A new nematode, Procamallanus pereirai, with a key to the genus. Trans. Amer. Microscop. Soc. 65, 4:299-303.

Baylis, HA, 1923: Some parasitic worms, mainly from fishes from Lake Tanganyika. Ann. Mag. Nat. Hist. 10, 1:552-62.

Baylis, HA, 1948: On two nematode parasites of fishes. Ann. Mag. Nat. Hist. 14, 113: 327-35. Fusco, AC, Overstreet, RM, 1979: Two camal lanid nematodes from Red Sea fishes including Procamallanus elatensis sp. nov. from siganids. J. Nat. Hist. 13, 1:35-40.

Geets, A, Ollevier, F, 1996: Endoparasitic helminthes of the white spotted rabbit fish (Siganus sutor valenciennes, 1835) of the Kenyan coast: distribution within the host population and microhabitat use. Belg. J. Zool. 126: 21-36.

Gibson, DI, 2017: Procamallanus Baylis, 1923: Accessed through: World Register of Marine Species at http://www.marinespecies.org/aphia. php? $p=$ taxdetails\&id $=390573$ on 2017-05-13.

Justine, JL, Briand, MJ, Bray, RA, 2012: A quick and simple method, usable in the field, for collecting parasites in suitable condition for both morphological and molecular studies. Parasitol. Res.111, 1:341-51.

Khera, S, 1955: On some species of Procamallanus Baylis, 1923 from India. Ana. Escuela Nacion. de Ciencias Biol. 8, 3/4: 243-52). Mexico.

Lee, MR, 1993: The petrography, mineralogy and origins of calcium sulphate within the Cold Bokkeveld CM carbonaceous chondrite. Meteoritics 28:53-62.

Lester, RJG, Sewell, KB, 1989: Checklist of parasites from Heron Island, Great-Barrier-Reef. Austral. J. Zool. 37, 1:101-28.

Lieske, E, Myers, RF, 1994: Collins Pocket Guide. Coral reef fishes: Caribbean, Indian Ocean, and Pacific Ocean including the Red Sea. London: Harper Collins.

Lieske, E, Myers, RF, 1996: Coral Reef Fishes: Caribbean, Indian Ocean and Pacific Ocean Including the Red Sea (Vol. 41). Princeton, NJ: Princeton University Press.

Lieske, E, Fiedler, KE, Myers, RF, 2004: Coral Reef Guide: Red Sea to Gulf of Aden, South Oman; [the Definitive Guide to Over 1200 Species of Underwater Life]. Collins.

Martens, E, Moens, J, 1995: The metazoan ecto-and endoparasites of the rabbitfish, Siganus sutor (Cuvier \& Valenciennes, 1835) of the Kenyan coast. I. Afri. J. Ecol. 33, 4:405-16.

Moravec, F, Sey, O, 1988: Nematodes of freshwater fishes from North Vietnam: Part 1-. Camallanoidea and Habronematoidea. Věstn. Česko. Společn. Zool. 52, 2:128-48.

Moravec, F, Scholz, T, 1991: Observations on the biology of Pomphorhynchus laevis (Zoega in Müller, 1776) (Acanthocephala) in the Rokytná River, Czech and Slovak Federative Republic. Helminthologia 28, 1:23-9

Moravec, F, Thatcher, VE, 1997: Procamallanus (Denticamallanus subgen. $\mathrm{n}$.) dentatus $\mathrm{n}$. sp. (Ne-matoda: Camallanidae) from the characid fish, Bryconops alburnoides, in the Brazilian Amazon. Parasite 4, 3:239-43.

Moravec, F, Justine, J, 2011: New data on the morphology of Procamallanus (Procamallanus) annulatus and Procamallanus (Spirocamallanus) monotaxis (Nematoda: Camallanidae) from marine fishes off New Caledonia. Helminthologia 48, 1:41-50.

Myers, BJ, Kuntz, RE, 1969: Nematodes of fishes, amphibians, and reptiles taken by US Naval Medical Research Unit No. 2 expedition 
to North Borneo (Malaysia). J. Fisheries Board of Canada. 26, 4:793-7.

Olsen, LS, 1952: Some nematodes parasitic in marine fishes: Publications of the Institute of Marine Science, University of Texas 11, 2:173215.

Parukhin, AM, 1971: Nematodes from fishes of the Red Sea and Indian Ocean. Voprosy ekologii ryb yuzhnykh morey. Biol. Morya 23: 177-93.

Randall, JE, 1982: The Diver's Guide to Red Sea Reef Fishes. Biblios Publication Distribution Service.

Sahay, U, Narayan, S, 1967: On the nematode family Camallanidae (Railliet and Henry, 1915) and its classification. Ann. Inst. Biol. Univ. Mex.'Ser. Zool. 38, 1:23-6.
Sahay, U, 1966: On a new key of the genus Procamallanus with a historical review. Jpn. J. Med. Sci. Biol. 19, 3:165-70.

Shing, YL, 1960: On a collection of Camallanid nematodes from freshwater fishes in Ceylon. J. Helminth. 34:107-16.

Yamaguti, S, 1935: Studies on the helminth fauna of Japan: Part 9- Nematodes of fishes, 1. Jpn. J. Zool. 6:337-86.

Yamaguti, S, 1941: Studies on the helminth fauna of Japan. Part 33. Nematodes of fishes, II. Jpn. J. Zool. 9, 3:343-96.

Yamaguti, S, 1955: Parasitic worms mainly from Celebes: Part 9- Nematodes of fishes. Acta Med. Okayama, 9: 122-33, Plts. I, II.

Yorke, W, Maplestone, PA, Stiles, CW, 1926: The nematode parasites of vertebrates. New York: Hafner Publishing Company.

\begin{tabular}{|c|c|c|c|}
\hline Reference & Fusco \& Overstreet, 1979 & El Abdou et al., 2001 & Present study \\
\hline Host(s) & $\begin{array}{l}\text { Siganus rivulatus \& Siganus } \\
\text { luridus }\end{array}$ & $\begin{array}{l}\text { Siganus rivulatus \& } \\
\text { Siganus luridus }\end{array}$ & $\begin{array}{l}\text { Siganus rivulatus, Siganus } \\
\text { luridus \& Siganus sutor }\end{array}$ \\
\hline Locality & Northern Gulf of Aquaba & Hurghada, Egypt & Sharm EL-Naga, Egypt \\
\hline Measured Parasite number & $29 ; 11 \delta \& 18$ \& & $10 ; 50 \& 50$ & $14 ; 50 \& 90$ \\
\hline Site of infection & Intestine, Abdominal cavity & intestine & intestine \\
\hline \multicolumn{4}{|l|}{ Male measurements } \\
\hline Body Length [L] & $12,600-15,800$ & $8,000-10,000(9,000)$ & $13,910-14,370(14,140)$ \\
\hline Maximum body Width [W] & $216-309$ & $200-250(230)$ & $189-239(214)$ \\
\hline Maximum body Width \%* & $(1.7-2)^{b}$ & $(2.5)^{b}$ & $1.4-1.7(1.5)$ \\
\hline Buccal capsule Length & $111-137$ & $100-120(110)$ & $101-106(104)$ \\
\hline Buccal capsule Length $\% *$ & $(0.8-0.9)^{b}$ & $(1.2-1.3(1.2))^{b}$ & $0.7-0.8 \quad(0.7)$ \\
\hline Buccal capsule Width & $87-111$ & $90-100(90)$ & $70-82(76)$ \\
\hline $\begin{array}{l}\text { buccal capsule width: buccal } \\
\text { capsule Length ratio }\end{array}$ & $(1: 1.23-1.28)^{\mathrm{b}}$ & $(1: 1.11-2.08(1: 2.09))^{b}$ & $1: 1.29-1.44(1: 1.37)$ \\
\hline Basal ring length & {$[42]^{\mathrm{a}}$} & - & $28-31(30)$ \\
\hline Basal ring breadth & {$[78]^{\mathrm{a}}$} & - & $50-52 \quad(51)$ \\
\hline circular ledge height & {$[20]^{\mathrm{a}}$} & - & $13-17(15)$ \\
\hline Muscular oesophagus L & $337-525$ & $370-450(410)$ & $356-396(376)$ \\
\hline Muscular oesophagus L\%* & $(2.7-3.3)^{b}$ & $(4.5-4.6(4.6))^{b}$ & $2.6-2.8 \quad(2.7)$ \\
\hline Muscular oesophagus W & $93-117$ & $60-90(80)$ & $73-77(75)$ \\
\hline Glandular oesophagus L & $662-946$ & $560-780(660)$ & $555-600(578)$ \\
\hline Glandular oesophagus L\%* & $(5.3-6)^{b}$ & $(7-7.8(7.3))^{b}$ & $4-4.2 \quad(4.1)$ \\
\hline Glandular oesophagus W & $95-155$ & $60-90(80)$ & $77-94 \quad(86)$ \\
\hline $\begin{array}{l}\text { Muscular oesophagus L: } \\
\text { glandular oesophagus L }\end{array}$ & $(1: 1.80-1.96)^{b}$ & $(1: 1.51-1.73(1: 1.61))^{b}$ & $1: 1.52-1.56(1: 1.54)$ \\
\hline Total oesophagus length & $1,098-1,255$ & $950-1,190(1,090)$ & $911-996(954)$ \\
\hline $\begin{array}{l}\text { Total oesophagus length } \\
\text { L\%* }\end{array}$ & $8-9$ & $(11.8-11.9)^{b}$ & $6.5-6.9 \quad(6.7)$ \\
\hline $\begin{array}{l}\text { Entire oes. \& buccal cap- } \\
\text { sule L }\end{array}$ & $(1,208-1,392)^{b}$ & $1,050-1,310(1200)^{\mathrm{b}}$ & $1,001-1,006(1,004)$ \\
\hline $\begin{array}{l}\text { Entire oes. \& buccal capsule } \\
\text { L\%* }\end{array}$ & $(8.8-9.6)^{b}$ & $(13.1(13.3))^{b}$ & $7.0-7.2 \quad(7.1)$ \\
\hline nerve ring $\mathrm{L}$ & - & - & $33-37 \quad(35)$ \\
\hline nerve ring breadth & $36-48$ & 90 & $61-77 \quad(69)$ \\
\hline
\end{tabular}


Table (1): Continued

\begin{tabular}{|c|c|c|c|}
\hline Pre-Nerve ring distance & $253-321$ & 120 & $188-195(192)$ \\
\hline Pre-Nerve ring distance $\% *$ & $(2)^{b}$ & $(1.2-1.5(1.3))^{\mathrm{b}}$ & $1.3-1.4(1.4)$ \\
\hline Pre-excretory pore ring distance & - & - & $495-524(510)$ \\
\hline Pre-excretory pore ring distance $\% *$ & - & - & $3.4-3.8(3.6)$ \\
\hline Large spicule length & $420-486$ & $290-570(420)$ & $204-336(270)$ \\
\hline Small spicule length & $138-195$ & $200-220(210)$ & 69-189 (129) \\
\hline $\begin{array}{l}\text { Small spicules: } \\
\text { large specule Length }\end{array}$ & $\begin{array}{l}1: 2.40-3.30 \quad(1: \\
2.90)\end{array}$ & $(1: 1.45-2.59(1: 2))^{b}$ & $1.78-2.96(2.37)$ \\
\hline Gubernaculum length & $41-63$ & - & $31-86(59)$ \\
\hline Tail length & $143-205$ & $500-550(520)$ & $112-115(114)$ \\
\hline Tail length $\% *$ & $(1.1-1.3)^{b}$ & $(0.5-0.6(0.6))^{b}$ & $0.7-0.8(0.8)$ \\
\hline Pre-Nerve ring distance & $253-321$ & 120 & $188-195(192)$ \\
\hline Caudal alae length & - & $290-400(340)$ & $395-412(404)$ \\
\hline Caudal alae length $\% *$ & - & $\left(3.6^{-4}(3.58)\right)^{b}$ & $2.8-2.9(2.9)$ \\
\hline \multicolumn{4}{|l|}{ Female measurements } \\
\hline Body Length [L] & $20,400-27,700$ & $\begin{array}{l}20,000-25,000 \\
(22,500)\end{array}$ & $27,490-31,260(28,940)$ \\
\hline Maximum body width [W] & $358-445$ & $460-580(520)$ & $376-427(394)$ \\
\hline Maximum body width \%* & $(1.6-1.8)^{b}$ & $(2.2-2.3(2.3))^{b}$ & $1.2-1.6(1.4)$ \\
\hline Buccal capsule Length & $136-173$ & $130-150(140)$ & $115-133(121)$ \\
\hline Buccal capsule Length $\% *$ & $(0.5-0.7)^{b}$ & $(0.6-0.7(0.6))^{b}$ & $0.4-0.5(0.4)$ \\
\hline Buccal capsule Width & $113-136$ & $110-140(130)$ & $91-101(95)$ \\
\hline $\begin{array}{l}\text { buccal capsule width: buccal capsule } \\
\text { Length ratio }\end{array}$ & $1: 1.20-1.27$ & $\begin{array}{l}(1: 1.07-1.18(1: 1.08) \\
)^{b}\end{array}$ & $1: 1.23-1.32(1: 1.27)$ \\
\hline Basal ring Length & {$[34]^{\mathrm{a}}$} & - & $26-30(28)$ \\
\hline Basal ring breadth & {$[58]^{\mathrm{a}}$} & - & $58-64(61)$ \\
\hline circular ledge height & {$[15]^{\mathrm{a}}$} & - & $13-25(18)$ \\
\hline Muscular oesophagus L & $488-593$ & $460-540(500)$ & $378-411(393)$ \\
\hline Muscular oesophagus L\%* & $(2.1-2.4)^{b}$ & $(2.2-2.3(2.2))^{b}$ & $1.3-1.5(1.4)$ \\
\hline Muscular oesophagus W & $74-130$ & $100-120(111)$ & $105-114(108)$ \\
\hline Glandular oesophagus L & $772-1214$ & $730-910(810)$ & $599-804(695)$ \\
\hline Glandular oesophagus L\%* & $(3.8-4.4)^{b}$ & $(3.6-3.7(0.36))^{b}$ & $1.9-2.9(2.4)$ \\
\hline Glandular oesophagus W & $68-136$ & - & $119-132(124)$ \\
\hline $\begin{array}{l}\text { Muscular oesophagus L : Glandular } \\
\text { oesophagus L }\end{array}$ & $(1: 1.58-2.05)^{b}$ & $\begin{array}{ll}(1: 1.591 .69 & (1: 1.62) \\
)^{b} & \end{array}$ & $1: 1.53-1.96(1: 1.76)$ \\
\hline Total oesophagus length & $1,292-1,307$ & $1,040-1,300(1,150)$ & $990-1,215(1,088)$ \\
\hline Total oesophagus length L\%* & $6-8$ & $(5.1-5.2(5.2))^{b}$ & $3.2-4.4(3.8)$ \\
\hline
\end{tabular}

\section{Explanation of figures}

Plate 1: Photomicrographs of adult male of nematode parasite Procamallanus (procamallanus) elatensis infecting Siganus rivulatus showing: A- Ventral view of anterior extremity. B- Enlarged cephalic end revealing buccal capsule. C- Enlarged cephalic end revealing the nerve ting, basal ring, buccal capsule and moth opening. D- Ventrolateral view of posterior extremity disclosing caudal alae, spines and gubernaculum. E- Lateral view of posterior extremity disclosing caudal alae, spines and cloaca.

Abbreviations; BC, buccal capsule; BR, basal ring; Ca, caudal alae; Cl; cloaca; GO, glandular oesophagus; Gu, gubernaculum; In, intestine; LS, long spine; MO, muscular oesophagus; Mo, mouth; NR, nerve ring; Ph, phasmid; SS, short spine Ta, tail.

Plate 2: Photomicrographs of adult female of nematode parasite Procamallanus (procamallanus) elatensis showing: A- Ventral view of anterior extremity showing buccal capsule and oesophagus portions. B- \& C- Enlarged cephalic end revealing buccal capsul, nerve ting, basal ring \& moth opening. D- Ventral view of posterior extremity disclosing long tail. E- \& G- Ventrolateral view of posterior extremity disclosing rectum \& anus. F- Ventral view of posterior extremity disclosing rectum, Phasmid \& anus.

Abbreviations; An, anus; $\mathrm{BC}$, buccal capsule; $\mathrm{BR}$, basal ring; $\mathrm{Ca}$, caudal alae; Cl; cloaca; GO, glandular oesophagus; In, intestine; MO, muscular oesophagus; Mo, mouth; NR, nerve ring; Ph, phasmid; Pr, proctodeum; Re, rectum; Ta, tail.

Plate 3: SEM adult nematode parasite Procamallanus (procamallanus) elatensis showing: A- Buccal capsule with lateral amphids and anterior deirids. B- Cephalic end revealing buccal capsule and excretory pore cover by Tegumental rounded process. C- High magnifications of body at mid of anterior third of body revealing striated cuticle. D- High magnifications of excretory pore region cover by tegumental rounded process. E- High magnifications of posterior extremity of male revealing long spine and caudal alae. F- Enlarged portion of tail of male showing caudal papillae. G- High magnifications of spine surface. H- Posterior extremity of female revealing transverse anus. 


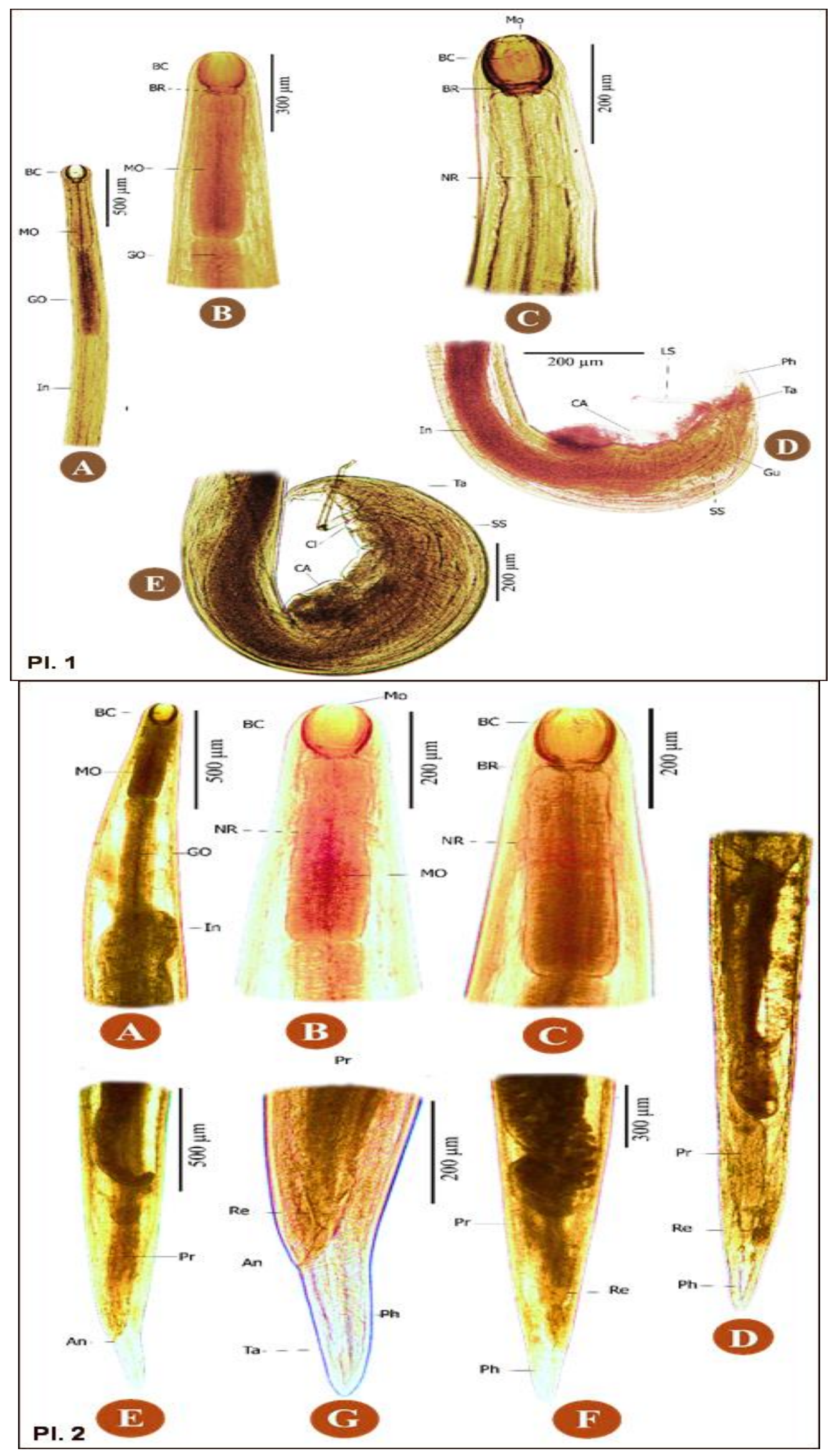




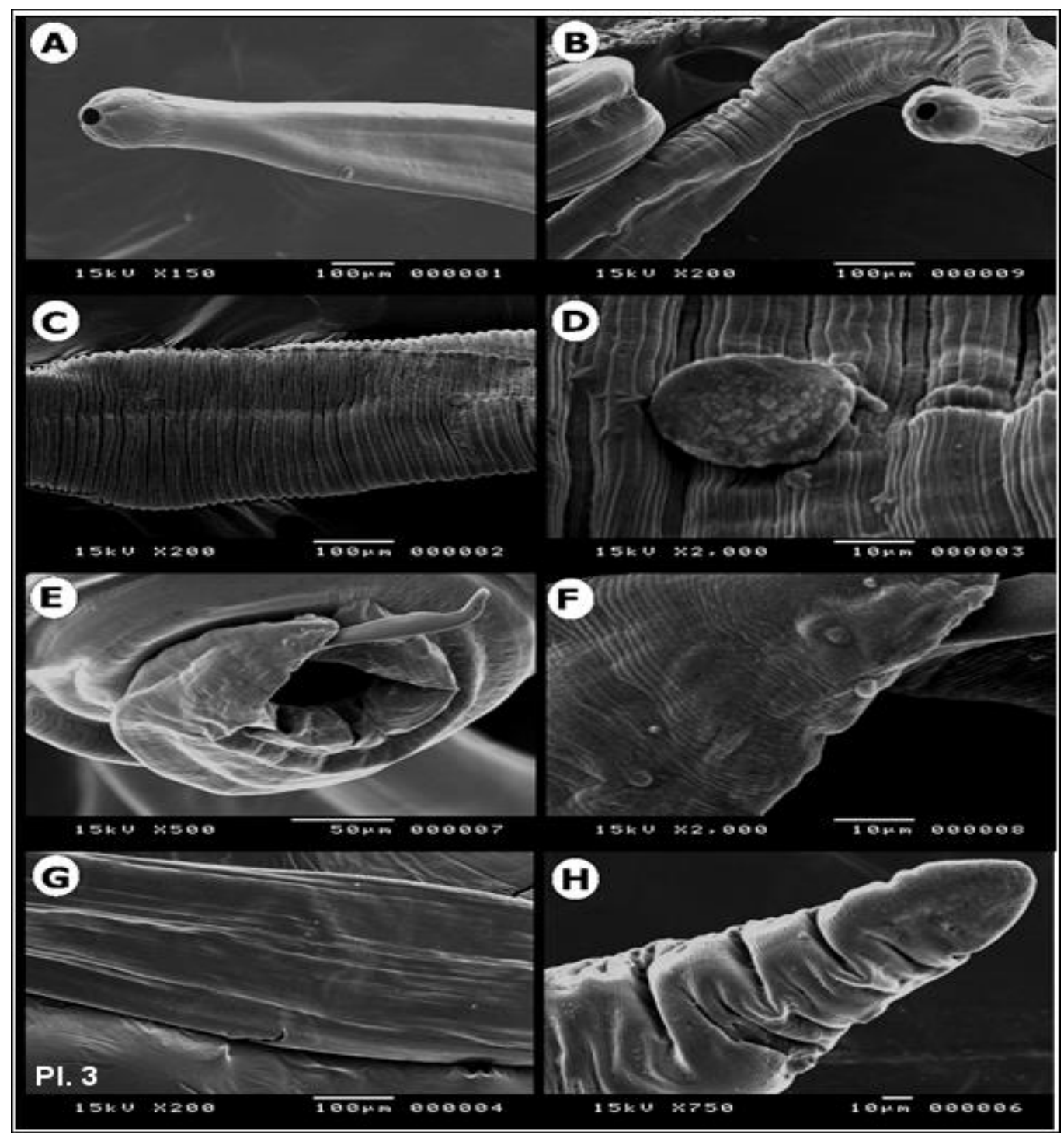

